\title{
COMPARISON OF SECULAR PARALLAXES DETERMINED \\ FROM PROPER MOTIONS OF STARS RELATIVE TO \\ GALAXIES AT THE PULKOVO AND LICK OBSERVATORIES
}

\author{
N. V. FATCHIKHIN \\ Pulkovo Observatory, U.S.S.R.
}

The secular parallaxes, determined by Klemola and Vasilevskis from proper motions of stars relative to galaxies (Klemola and Vasilevskis, 1971), were interpolated in latitude for each area of the Pulkovo Catalogue (Fatchikhin, 1974). Then the mean values were grouped in three zones of galactic latitude $(b)$ and the data obtained at the Lick Observatory $(L)$ were compared with our data $(P)$ (Fatchikhin, 1972, 1973). The results are given in the Table I.

TABLE I

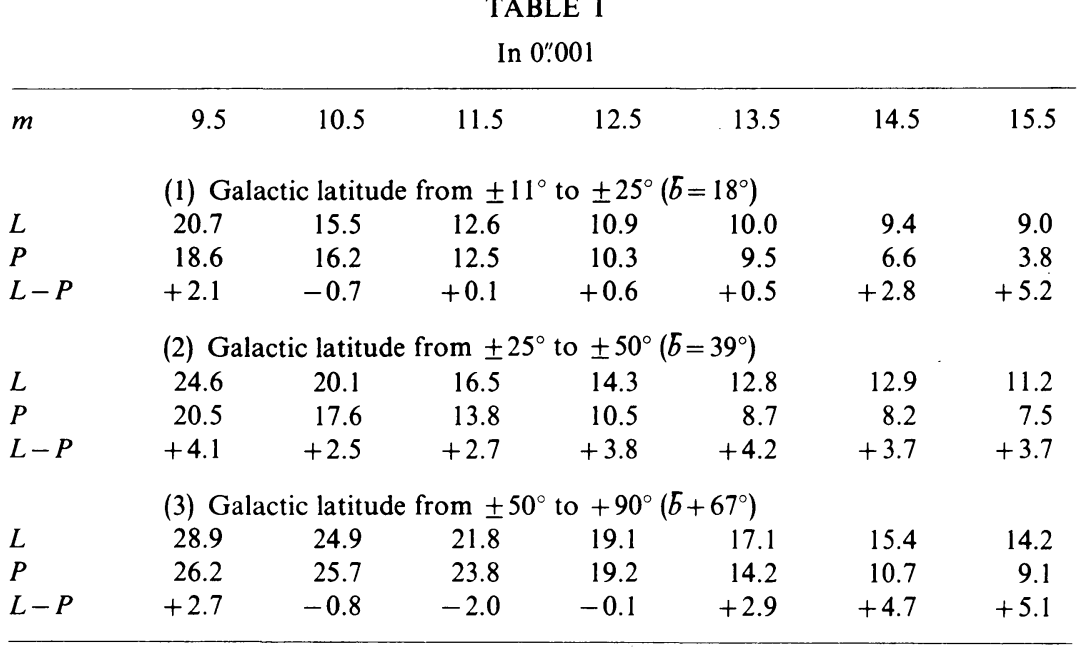

As seen from the table the greatest deviation in the parallaxes is in the middle zone $\left(b=38^{\circ}\right): \overline{L-P}=+0$ ".0035.

Previously we compared our results with those obtained at the Groningen, McCormick, Radcliffe Observatories and also with the Pulkovo results in Kapteyn's areas (Fatchikhin, 1972, 1973). On the base of this comparison we conclude that secular parallaxes of stars in high galactic latitudes $\left(b=67^{\circ}\right)$ obtained recently at the Pulkovo and the Lick Observatories appeared to be larger than the data of the above mentioned Observatories. The mean values of secular parallaxes were calculated from our data (Fatchikhin, 1974) in the $10^{\circ}$ zones of galactic latitude and the $90^{\circ}$ longitude (Fatchikhin, 1972, 1973). The wave-like variations of these parallaxes have been detected, which could be explained by rotation of a local star system. 


\section{References}

Fatchikhin, N. V.: 1974, 'Catalogue of 14600 Stars', Trudy Pulkovo Obs. 81, in press.

Fatchikhin, N. V.: 1972, Astron. Circ. Acad. Sci. U.S.S.R., No. 668.

Fatchikhin, N. V.: 1973, Astron. Zh. 50, 2.

Klemola, A. R. and Vasilevskis, S.: 1971, Publ. Lick Obs. 22, 111. 